Dikirim: 6 Desember 2016 Diterbitkan: 1 Januari 2017

\section{Paparan informasi kesehatan reproduksi melalui media pada perilaku seksual pranikah: analisis data survei demografi kesehatan Indonesia 2012}

The correlation of reproductive health information exposure from media on premarital sexual behaviour: an Indonesia demographic health survey 2012 analysis

Puspasari ${ }^{1}$, Sukamdi $^{1}$, Ova Emilia ${ }^{2}$

\begin{abstract}
Purpose: This study aimed to determine the correlation of type and intensity of exposure of reproductive health information through media to the sexual behavior of adolescents and young adults in Indonesia. Methods: This study used a cross-sectional design. The data used was the Indonesian sub-survey of adolescent reproductive health, Indonesia demographic and health Survey. Results: The results showed that adolescents and young adults who receive the health information type of adolescent reproductive health category have a smaller prevalence in sexual intercourse before marriage than information of contraceptive methods category or both. The intensity of exposure to reproductive health information which was low or no exposure, have higher prevalence of premarital sexual behavior. Age, gender, level of education, level of wealth, smoking, drinking alcohol, drug consumption and dating intimacy are significantly associated with premarital sexual behavior of adolescents and young adults. Conclusion: Type and intensity of reproductive health information are significantly associated with premarital sexual behavior of adolescents and young adults. The high intensity of exposure and type of adolescent reproductive Health category have a smaller prevalence in sexual intercourse before marriage.
\end{abstract}

Keywords: health information; intensity of exposure; premarital sexual behavior; adolescents

\footnotetext{
${ }^{1}$ Departemen Biostatistik, Epidemiologi dan Kesehatan Populasi, Fakultas Kedokteran, Universitas Gadjah Mada

(Email: puspasarimph@gmail.com)

${ }^{2}$ Departemen Obstetri dan Ginekologi, Fakultas Kedokteran, Universitas Gadjah Mada
} 


\section{PENDAHULUAN}

Jumlah remaja berkaitan dengan beberapa masalah sosial, ekonomi, dan kesehatan. Masalah kesehatan reproduksi yang sering timbul adalah perilaku seks berisiko, kehamilan di luar pernikahan, pernikahan dini, aborsi dan penyakit menular seksual seperti HIV dan AIDS. Seksual pranikah pada remaja wanita di Indonesia sebesar $1 \%$ dan remaja pria $8,3 \%$ (1). Prevalensi pranikah meningkat sebesar $1,9 \%$ pada pria dibandingkan dengan suvei kesehatan reproduksi remaja Indonesia (SKRRI) tahun 2007 (2).

Pengetahuan tentang kesehatan reproduksi yang kurang menjadikan kebutuhan informasi menjadi hal penting terutama dalam perencanaan reproduksi, penanggulangan HIV/AIDS dan ketergantungan napza (3). Pengetahuan informasi seksualitas yang baik memberikan peluang waktu berpantang lebih lama untuk melakukan hubungan seksual pranikah pada remaja (4). Namun, jika pesan tersembunyi paparan media mengandung muatan pornografi akan merangsang ketertarikan remaja melakukan seks (5).

Paparan informasi seksualitas melalui media baik yang bersifat eksplisit maupun implisit menimbulkan kerentanan bagi remaja untuk melakukan perilaku seksual pranikah. Paparan media beberapa negara jarang menyajikan promosi kesehatan reproduksi yang bertanggung jawab bagi remaja (6). Penelitian lain menyebut remaja lebih besar terpapar konten seksual di media (7). Penelitian ini bertujuan mengetahui hubungan jenis dan intensitas paparan informasi kesehatan reproduksi melalui media terhadap perilaku seksual pada remaja dan dewasa muda di Indonesia.

\section{METODE}

Penelitian ini menggunakan rancang bangun cross sectional study. Data yang digunakan adalah data survei demografi dan kesehatan Indonesia (SDKI) tahun 2012 sub survei kesehatan reproduksi remaja (KRR). Penelitian melibatkan 9.551 remaja dari 33 provinsi Indonesia. Kriteria sampel penelitian adalah remaja berusia 15-24 tahun, belum menikah, mendapat akses informasi kesehatan reproduksi dari media

Variabel bebas adalah jenis dan intensitas paparan informasi kesehatan reproduksi melalui media. Variabel terikat adalah perilaku seksual pranikah (koitus). Variabel luar adalah tingkat pendidikan, jenis kelamin, umur, tingkat kekayaan, pubertas, domisili, perilaku berisiko (merokok, minum alkohol dan kosumsi napza) dan keintiman berpacaran. Analisis statistik melalui uji chi-square dan regresi logistik.
HASIL

Tabel 1 menunjukkan perilaku konsumsi alkohol, rokok dan napza. Responden yang merokok menunjukkan frekuensi tertinggi dibandingkan perilaku berisiko lain. Keintiman berpacaran menunjukkan lebih dari sepertiganya termasuk kategori tidak intim dan intim.

Tabel 1. Ciri responden

\begin{tabular}{|c|c|}
\hline Karakteristik & $\%$ \\
\hline \multicolumn{2}{|l|}{ Perilaku seksual pranikah } \\
\hline Koitus (n=733) & 7,37 \\
\hline Tidak Koitus (n=9218) & 92,63 \\
\hline \multicolumn{2}{|l|}{ Jenis informasi } \\
\hline Kesehatan reproduksi $(n=977)$ & 9,82 \\
\hline Metode kontrasepsi $(\mathrm{n}=1.194)$ & 12,00 \\
\hline $\begin{array}{l}\text { Menerima informasi keduanya } \\
(n=6.110)\end{array}$ & 61,40 \\
\hline Tidak menerima $(n=1.670)$ & 9,82 \\
\hline \multicolumn{2}{|l|}{ Intensitas paparan } \\
\hline Tidak terpapar $(\mathrm{n}=1.003)$ & 10,08 \\
\hline Rendah $(n=4.576)$ & 45,99 \\
\hline Sedang $(n=2.702)$ & 27,15 \\
\hline Tinggi $(\mathrm{n}=1.670)$ & 16,78 \\
\hline \multicolumn{2}{|l|}{ Umur } \\
\hline Remaja (15-19 tahun) $(n=6.322)$ & 63,22 \\
\hline $\begin{array}{l}\text { Dewasa muda (20-24 tahun) } \\
(\mathrm{n}=3.629) \\
\text { Jenis kelamin }\end{array}$ & 36,29 \\
\hline Laki-laki (n=5.098) & 51,23 \\
\hline Perempuan $(\mathrm{n}=4.853)$ & 48,77 \\
\hline \multicolumn{2}{|l|}{ Tingkat pendidikan } \\
\hline$S D(n=557)$ & 5,60 \\
\hline $\operatorname{SMP}(n=1.975)$ & 19,85 \\
\hline SMA $(n=5.242)$ & 52,68 \\
\hline Diploma/PT $(\mathrm{n}=2.177)$ & 21,88 \\
\hline \multicolumn{2}{|l|}{ Domisili } \\
\hline Kota $(n=6.275)$ & 63,06 \\
\hline Desa $(n=3.676)$ & 36,94 \\
\hline \multicolumn{2}{|l|}{ Tingkat kekayaan } \\
\hline Sangat miskin $(\mathrm{n}=1.481)$ & 14,88 \\
\hline Miskin $(\mathrm{n}=1.864)$ & 18,73 \\
\hline Menengah $(n=1.996)$ & 20,06 \\
\hline Kaya $(n=2.095)$ & 21,05 \\
\hline Sangat kaya $(n=2.515)$ & 25,27 \\
\hline \multicolumn{2}{|l|}{ Pubertas } \\
\hline Sudah $(n=9.693)$ & 97,41 \\
\hline Belum $(n=258)$ & 2,59 \\
\hline \multicolumn{2}{|l|}{ Konsumsi alkohol } \\
\hline $\mathrm{Ya}(\mathrm{n}=2.523)$ & 25,35 \\
\hline Tidak (n=7.428) & 74,65 \\
\hline \multicolumn{2}{|l|}{ Konsumsi rokok } \\
\hline $\mathrm{Ya}(\mathrm{n}=4.730)$ & 47,53 \\
\hline Tidak (n=5.221) & 52,47 \\
\hline \multicolumn{2}{|l|}{ Konsumsi napza } \\
\hline Ya $(n=263)$ & 2,64 \\
\hline Tidak $(n=9.688)$ & 97,36 \\
\hline \multicolumn{2}{|l|}{ Keintiman berpacaran } \\
\hline Tidak pacaran $(\mathrm{n}=1.236)$ & 12,42 \\
\hline Tidak intim $(n=4.446)$ & 44,68 \\
\hline Intim $(\mathrm{n}=4.269)$ & 42,90 \\
\hline
\end{tabular}

Tabel 2 menunjukkan hubungan antara jenis informasi kesehatan dengan perilaku seksual pranikah remaja dan dewasa muda. Selain itu, semua kategori jenis infomasi kesehatan bermakna signifikan secara statistik dengan perilaku koitus (terlihat dari nilai CI). Responden yang mendapatkan informasi kesehatan 
kategori menerima keduanya (kesehatan reproduksi dan metode kontrasepsi) memiliki proporsi paling besar dalam melakukan perilaku seksual pranikah dibandingkan dengan yang memperoleh informasi kesehatan kategori lain.

Tabel 2. Risk prevalence perilaku seksual pranikah

\begin{tabular}{lrrrrr}
\hline \multicolumn{1}{c}{ Variabel } & \multicolumn{2}{c}{$\begin{array}{c}\text { Perilaku } \\
\text { Pranikah }\end{array}$} & & \\
\cline { 2 - 3 } & $\begin{array}{c}\text { Koitus } \\
\text { (n) }\end{array}$ & $\begin{array}{c}\text { Tidak } \\
\text { koitus (n) }\end{array}$ & & 95\%CI \\
\cline { 1 - 2 } Jenis informasi kesehatan & & & & \\
Kesehatan reproduksi & 62 & 915 & 0,75 & $0,583-0,971^{*}$ \\
Metode kontrasespi & 66 & 1.128 & 0,65 & $0,511-0,840^{*}$ \\
Menerima keduanya & 515 & 5.595 & & \\
Tidak menerima & 90 & 1.580 & 0,64 & $0,514-0,794^{*}$ \\
Intensitas paparan & & & & \\
Tinggi & 90 & 1.580 & & \\
Sedang & 285 & 4.291 & 0,65 & $0,531-0,797^{*}$ \\
Rendah & 228 & 2.474 & 0,48 & $0,395-0,584^{*}$ \\
Tidak terpapar & 130 & 873 & 0,41 & $0,321-0,537^{*}$ \\
\hline Keterangan: *signifikan (p<0,05) & & &
\end{tabular}

Remaja yang terpapar informasi kategori tinggi memiliki proporsi paling rendah dalam melakukan perilaku seksual pranikah dibandingkan dengan kategori lainnya. Perilaku koitus tertinggi terjadi pada responden yang tidak terpapar infomasi kesehatan. Intensitas paparan memiliki hubungan yang signifikan dan bermakna dengan perilaku seksual pranikah baik paparan sedang, rendah dan tidak terpapar. Analisis hubungan variabel luar dengan perilaku seksual pranikah menunjukkan hubungan variabel luar dengan terikat. Penelitian menunjukkan ada hubungan antara umur, jenis kelamin, tingkat pendidikan, tingkat kekayaan, perilaku berisiko (merokok, minum alkohol, konsumsi napza), dan keintiman berpacaran dengan perilaku seksual pranikah.

Pemodelan ini dibuat untuk mengetahui pengaruh variabel luar terhadap terjadinya perilaku seksual pranikah remaja untuk masing-masing variabel bebas. Variabel yang diuji pada analisis ini ditentukan dari variabel yang mempunnyai nilai $\mathrm{p}<0,05$ pada uji bivariabel. Tabel 3 menunjukkan model terakhir yang dibuat dengan memasukkan variabel bebas intensitas paparan dengan melihat pengaruh variabel luar yaitu jenis kelamin, umur, tingkat pendidikan, sosial ekonomi, perilaku merokok, konsumsi alkohol, napza dan keintiman berpacaran. Penambahan semua variabel luar memengaruhi perubahan signifikansi dan kenaikan nilai OR untuk variabel intensitas paparan. Perubahan signifikansi juga terjadi pada variabel tingkat pendidikan. Hal ini menunjukkan bahwa variabel lain dalam model ini adalah confounding. Perubahan signifikansi menjadi tidak signifikan pada tingkat pendidikan menunjukkan bahwa faktor tersebut tidak diperhitungkan dalam variabel intensitas paparan. Model ini disimpulkan sebagai model yang efektif karena memiliki nilai tes statistik yang paling baik dibanding model lain.

Tabel 3. Model multivariabel akhir

\begin{tabular}{|c|c|c|}
\hline Variabel & Odds Ratio & 95\%CI \\
\hline \multicolumn{3}{|l|}{ Intensitas paparan } \\
\hline Tidak terpapar & 0,73 & $(0,523-1,043)$ \\
\hline Rendah & 0,70 & $(0,545-0,914) *$ \\
\hline Sedang & 0,75 & $(0,579-0,982)^{*}$ \\
\hline Tinggi (ref) & & 1 \\
\hline \multicolumn{3}{|l|}{ Umur (tahun) } \\
\hline Remaja(15-19) (ref) & & 1 \\
\hline Dewasa muda (20-24) & 1,82 & $(1,507-2,203)^{*}$ \\
\hline \multicolumn{3}{|l|}{ Jenis Kelamin } \\
\hline Perempuan (ref) & & 1 \\
\hline Laki-laki & 1,89 & $(1,370-2,625)^{*}$ \\
\hline \multicolumn{3}{|l|}{ Tingkat Pendidikan } \\
\hline SD & 1,13 & $(0,777-1,650)$ \\
\hline SMP & 0,94 & $(0,706-1,261)$ \\
\hline SMA & 0,81 & $(0,650-1,019)$ \\
\hline Diploma/PT (ref) & & 1 \\
\hline \multicolumn{3}{|l|}{ Tingkat kekayaan } \\
\hline Sangat miskin & 2,06 & $(1,525-2,781)^{*}$ \\
\hline Miskin & 1,85 & $(1,407-2,450)^{*}$ \\
\hline Menengah & 1,39 & $(1,061-1,827)^{*}$ \\
\hline Kaya & 1,05 & $(0,796-1,389)$ \\
\hline Sangat kaya (ref) & & 1 \\
\hline \multicolumn{3}{|l|}{ Konsumsi alkohol } \\
\hline Ya & 3,98 & $(3,206-4,960)^{*}$ \\
\hline \multicolumn{3}{|l|}{ Tidak } \\
\hline \multicolumn{3}{|l|}{ Konsumsi rokok } \\
\hline Ya & 1,58 & $(1,139-2,210)^{*}$ \\
\hline \multicolumn{3}{|l|}{ Tidak } \\
\hline \multicolumn{3}{|l|}{ Konsumsi napza } \\
\hline $\begin{array}{l}\text { Ya } \\
\text { tidak }\end{array}$ & 2,46 & $\begin{array}{c}(1,856-3,260)^{*} \\
1\end{array}$ \\
\hline \multicolumn{3}{|l|}{ Keintiman Berpacaran } \\
\hline Tidak pacaran & & 1 \\
\hline Tidak intim & 0,63 & $(0,196-2,027)$ \\
\hline Intim & 24,11 & $(8,920-65,21)^{*}$ \\
\hline
\end{tabular}

\section{BAHASAN}

Penelitian menunjukkan bahwa remaja dan dewasa muda yang melakukan hubungan seksual pranikah sebanyak 7,34\%. Capaian tersebut menggambarkan perilaku seksual pranikah di Indonesia berdasarkan akses informasi kesehatan reproduksi melalui media (televisi, radio dan majalah). Secara umum prevalensi nasional perilaku seksual pranikah remaja meningkat dari tahun 2007 ke tahun 2012. Peningkatan mencapai 1,9\% pada remaja laki-laki, namun cenderung konstan pada remaja perempuan.

Penelitian ini secara umum menjelaskan bagaimana jenis dan intensitas paparan informasi kesehatan reproduksi yang diterima remaja dan dewasa muda melalui media berhubungan dengan perilaku seksual pranikah (koitus). Remaja yang telah aktif secara 
seksual menerima informasi kesehatan reproduksi dari berbagai sumber (8). Pengetahuan tentang kesehatan reproduksi, secara teori dapat mencegah remaja untuk melakukan perilaku seksual berisiko. Apalagi saat ini sekolah dan fasilitas kesehatan telah menyediakan layanan dan program terkait isu tersebut (9).

Konsekuensi logis terjadi pada pemahaman yang benar dan komprehensif tentang kesehatan reproduksi menurunkan prevalensi perilaku seksual pranikah pada remaja. Informasi positif tentang kesehatan reproduksi dari media dapat membawa remaja ke dalam perilaku seksual yang sehat (10). Namun hasil penelitian ini menunjukkan remaja dan dewasa muda yang mendapatkan informasi (kesehatan reproduksi dan metode kontrasepsi dari media memiliki proporsi lebih besar untuk berperilaku seksual pranikah dibandingkan remaja yang tidak memperoleh informasi atau hanya mendapatkan satu jenis informasi. Remaja yang hanya menerima jenis informasi kategori kesehatan reproduksi memiliki prevalensi terkecil untuk melakukan koitus. Sedangkan analisis intensitas paparan menunjukkan semakin tinggi paparan informasi yang diterima remaja dan dewasa muda maka prevalensi untuk melakukan perilaku seksual pranikah semakin kecil, baik jenis dan intensitas paparan informasi kesehatan reproduksi. Kedua variabel tersebut berhubungan.

Penelitian ini menunjukkan responden yang hanya menerima informasi jenis metode kontrasepsi atau kesehatan reproduksi memiliki prevalensi yang lebih kecil dalam melakukan koitus dibandingkan yang menerima kedua jenis informasi tersebut. Penelitian lain yang serupa menyatakan bahwa promosi metode kontrasepsi melalui media seperti majalah, radio dan televisi secara signifikan mengubah pengetahuan, perilaku dan praktik penggunaan alat kontrasepsi bagi remaja dan dewasa muda yang sudah aktif secara seksual (11).

Remaja dan dewasa muda banyak menggunakan media dan terpapar informasi yang berisi seksualitas, namun sangat sedikit yang memaparkan konsekuensi dari perilaku dan pesan positif tentang kesehatan reproduksi (12). Salah satu penyebab intensitas paparan tinggi dari media tidak menjadikan remaja terhindar dari perilaku seksual pranikah. Lama akses, penggunaan dan isi pesan dari media massa menjadi faktor yang memengaruhi pengetahuan, sikap dan perilaku seks pada remaja dan dewasa muda (13). Keterbatasan penelitian ini salah satunya terlihat dari keterbatasan bukti pengukuran frekuensi, jenis pesan dan informasi yang diakses dan besarnya pengetahuan yang dimiliki oleh remaja.
Penelitian menunjukkan model yang memasukkan faktor intensitas paparan informasi dengan cara mempertimbangkan faktor lain lebih efektif secara nilai statistik dalam memprediksi pengaruh jenis dan informasi kesehatan reproduksi terhadap perilaku seksual pranikah. Paparan yang terjadi terus menerus tentang informasi positif akan membentuk pandangan dan kebiasaan yang positif dalam kehidupan nyata (14). Perilaku dan penerimaan stereotip seksual dari media berhubungan dengan pengulangan yang terus menerus tentang seksualitas $(15,16)$.

Analisis pengaruh jenis dan intensitas paparan informasi kesehatan reproduksi melalui media terhadap perilaku seksual dipengaruhi oleh banyak faktor. Faktor lain yang ikut berpengaruh pada perilaku seksual pranikah (koitus) dari hasil penelitian ini adalah umur, jenis kelamin, tingkat pendidikan, perilaku konsumsi alkohol, napza dan merokok serta keintiman berpacaran. Orang dengan kategori dewasa muda menunjukkan prevalensi yang lebih tinggi dalam melakukan seksual pranikah dibandingkan remaja. Menurut jenis kelamin, laki-laki paling banyak melakukan perilaku seksual pranikah. Remaja dan dewasa muda yang berpendidikan tinggi dan kondisi sosial ekonomi menengah ke atas menunjukkan risiko yang lebih kecil dalam melakukan perilaku seksual pranikah. Perilaku berisiko berupa gaya berpacaran yang intim, konsumsi alkohol dan napza berkontribusi besar dalam menimbulkan perilaku seksual pranikah

Faktor individu yang memungkinkan perilaku seksual pranikah remaja berupa perilaku berisiko seperti merokok, minum alkohol napza dan gaya berpacaran yang intim. Penelitian menjelaskan dari ketiga faktor tersebut, proporsi tertinggi dalam melakukan koitus berasal dari remaja yang minum alkohol. Remaja yang terlibat dalam perilaku berisiko seperti penggunaan napza, konsumsi alkohol dan perilaku antisosial lainnya seringkali melakukan hubungan seksual pada usia dini (17). Perilaku berisiko remaja merupakan manifestasi kematangan yang terlalu cepat dari teman sebaya (18). Selain itu, penerimaan perilaku tersebut secara normatif oleh kelompok teman sebaya atau yang lebih dewasa memungkinkan terjadi koitus (19). Gaya berpacaran intim memicu terjadinya perilaku seksual pranikah. Aktivitas seksual dengan pasangan mengikuti suatu rangkaian proses peningkatan, mulai dari sentuhan, ciuman, rabaan dan hubungan seksual (20). 


\section{SIMPULAN}

Prevalensi perilaku seksual pranikah remaja dan dewasa muda di Indonesia berdasarkan data SDKI 2012 sebesar 7,34\% lebih tinggi dibandingkan prevalensi tahun 2007 sekitar 6,1\%. Remaja dan dewasa muda yang terpapar informasi kesehatan kategori kesehatan reproduksi memiliki proporsi yang lebih sedikit dalam melakukan perilaku seksual pranikah dibandingkan dengan yang mendapat informasi kesehatan kategori lainnya. Semua ketegori jenis informasi kesehatan reproduksi menunjukkan hubungan yang signifikan dengan perilaku seksual pranikah. Intensitas paparan informasi yang rendah/tidak terpapar menunjukkan perilaku seksual pranikah dengan prevalensi tinggi. Intensitas paparan berhubungan secara signifikan dengan perilaku seksual pranikah.

\footnotetext{
Abstrak

Tujuan: Penelitian bertujuan untuk mengetahui hubungan jenis dan intensitas paparan informasi kesehatan reproduksi melalui media terhadap perilaku seksual pranikah di Indonesia. Metode: Penelitian rancangan cross sectional study ini dilakukan menggunakan data survei demografi dan kesehatan Indonesia (SDKI) tahun 2012 sub survei kesehatan reproduksi remaja (KRR). Hasil: Penelitian menunjukkan remaja dan dewasa muda yang menerima jenis informasi kesehatan kategori kesehatan reproduksi memiliki prevalensi yang lebih kecil dalam melakukan hubungan seksual pranikah dibandingkan informasi kategori metode kontrasepsi atau keduanya. Intensitas paparan informasi kesehatan reproduksi yang rendah atau tidak terpapar menunjukkan prevalensi perilaku seksual pranikah yang tinggi. Faktor umur, jenis kelamin, tingkat pendidikan, tingkat kekayaan, perilaku merokok, minum alkohol, konsumsi napza dan keintiman berpacaran berhubungan signifikan dengan perilaku seksual pranikah remaja dan dewasa muda. Simpulan: Jenis dan intensitas paparan informasi berhubungan signifikan dengan perilaku seksual pranikah. Intensitas paparan yang tinggi dan jenis informasi kategori kesehatan reproduksi memiliki prevalensi melakukan perilaku koitus dibandingkan kategori lainnya.
}

Kata kunci: infomasi kesehatan; intensitas paparan; perilaku seksual pranikah; remaja

\section{PUSTAKA}

1. Badan Pusat Statistik. Survei demografi dan kesehatan Indonesia 2012. Jakarta: Kementrian Kesehatan RI. 2013.

2. Bapak Pusat Statistik. Survei demografi dan kesehatan Indonesia 2007. BPS-BKKBN-Depkes RI-UNFPA. 2008.

3. Tukiran, D., Joko Pitoyo, A. \& Kutanegara, P. M. Kebijakan keluarga berencana dan kesehatan reproduksi menuju ke MDGs. Keluarga berencana dan kesehatan reproduksi. Yogyakarta Pusat Studi Kependudukan dan Kebijakan, Universitas Gadjah Mada;2010.

4. Pinandari, A. W. Pendidikan Kesehatan Reproduksi Formal Sebagai Pencegahan Perilaku Hubungan Seksual Pranikah Remaja dan Dewasa Muda di Indonesia (Analisis Data SDKI 2012). Ilmu Kesehatan Masyarakat, Thesis, Universitas Gadjah Mada;2015.

5. Dewi AP. Hubungan karakteristik remaja, peran teman sebaya dan paparan pornografi dengan perilaku seksual remaja di kelurahan pasir gunung selatan depok. Universitas Indonesia. 2012.

6. Brown JD. Mass Media Influence on Sexuality. Journal of Sex Research 2002; 39(1): 42-45.

7. L'Engle KL, Brown JD, Kenneavy K. The mass media are an important context for adolescents' sexual behavior. Journal of Adolescent Health. 2006 Mar 1;38(3):186-92.

8. Wellings K, Collumbien M, Slaymaker E, Singh S, Hodges Z, Patel D, Bajos N. Sexual behaviour in context: a global perspective. The Lancet. 2006 Nov 11;368(9548):1706-28.

9. Kirby, D. Risky Sexual Behavior. In: Editors-in-Chief, B. B. B. \& Mitchell, J. P. (eds.) Encyclopedia of Adolescence. San Diego: Academic Press;2011.

10. Wusu O. Exposure to media content and sexual health behaviour among adolescents in Lagos metropolis, Nigeria. African journal of reproductive health. 2013 Jun 1;17(2):157-68.

11. Borzekowski, Dina L.G., Media and contraceptive. Society for adolescent medicine New York;2000.

12. Huston AC, Wartella E, Donnerstein E. Measuring the Effects of Sexual Content in the Media: A Report to the Kaiser Family Foundation;1998.

13. Lou C, Cheng Y, Gao E, Zuo X, Emerson MR, Zabin LS. Media's contribution to sexual knowledge, attitudes, and behaviors for adolescents and young adults in three Asian cities. Journal of Adolescent Health. 2012 Mar 1;50(3):S26-36.

14. Taylor-Seehafer M, Rew L. Risky sexual behavior among adolescent women. Journal for Specialists in Pediatric Nursing. 2000 Jan 1;5(1):15-25.

15. Viner RM, Ozer EM, Denny S, Marmot M, Resnick M, Fatusi A, Currie C. Adolescence and the social determinants of health. The lancet. 2012 Apr 28;379(9826):1641-52.

16. Wallmyr G, Welin C. Young people, pornography, and sexuality: sources and attitudes. The Journal of School Nursing. 2006 Oct;22(5):290-5.

17. Poulin F. Individual, familial, friends-related and contextual predictors of early sexual intercourse. Journal of adolescence. 2011 Apr 1;34(2):289-300.

18. Igra, V. \& Irwin, C. E. Risk and risk-taking in adolescents. Social Pediatrics. 1995. 
19. DiClemente RJ, Santelli JS, Crosby RA, editors. Adolescent health: Understanding and preventing risk behaviors. John Wiley \& Sons; 2009 Apr 27.
20. Friedman, M.M., Bowden, V.R., \& Jones, E.G. Family Nursing: Research Theory \& Practice, New Jersey: Prentice Hall;2003. 